DOI: $10.6060 / \mathrm{mhc} 2012.120254 \mathrm{k}$

\title{
Influence of Tetrakis(4'-decaoxyphenyl)porphyrin Addition on Electrochemical Reduction of Oxygen on Pt Electrode in Dimethylformamide
}

\author{
Ivan A. Popov, ${ }^{a}$ Sergey M. Kuzmin, ${ }^{a @ ~ S v e t l a n a ~ A . ~ C h u l o v s k a y a, ~}{ }^{a}$ \\ Alexander S. Semeikin, ${ }^{b}$ and Vladimir I. Parfenyuk ${ }^{a}$ \\ ${ }^{\mathrm{a}} G$.A. Krestov Institute of Solution Chemistry of RAS, 153045 Ivanovo, Russia \\ 'Ivanovo State University of Chemistry and Technology, 153000 Ivanovo, Russia \\ @Corresponding authorE-mail:smk@isc-ras.ru
}

\begin{abstract}
Effects of tetrakis(4'-decaoxyphenyl)porphyrin on the electrochemical reduction of oxygen on Pt electrode in dimethylformamide were studied by method of cyclic voltamperometry with rotating disk electrode. The oxygen electrochemical reduction is identified as a wide (from -0.75 to $-1.5 \mathrm{~V}$ respect saturated calomel electrode) irreversible peak which disappears in oxygen free solutions. The current of electrochemical reduction of oxygen increases with the rotating rate of the electrode. The dependence of current on the square root of the working electrode rotation rate is a straight line, not extrapolated to zero of coordinate system. It allows us to conclude that electrochemical reduction of oxygen is limited by convective diffusion and kinetic processes. This condition can be analyzed using the KouteckyLevich equation.

As it shown by calculation the addition of tetrakis(4'-decaoxyphenyl)porphyrin decreases both the diffusion and the kinetic limitations of electrode reactions. The decrease of the diffusion limitations can be explained if in the area near electrode the oxygen concentration are shifted due to catalyzed by porphyrin molecules decay of superoxide ions. The fact of kinetic current increasing can propose the following catalytic process of electrochemical reduction of oxygen on Pt electrode in the porphyrin presence:

1.The admixture of water is a source of protons in aprotic medium: $\mathrm{H}_{2} \mathrm{O} \rightarrow \mathrm{H}^{+}+\mathrm{OH}^{-}$

2. The negative potential of working electrode leads to a migration of protons and the acidification of the near electrode area of the solution.

3. The acidic media leads to the formation of the protonated form of porphyrin in the near electrode area of the solution: $H^{+}+H_{2} P \leftrightarrow H_{3} P^{+}$

4.Protonated form of porphyrin forms an adduct with the dissolved oxygen: $\mathrm{H}_{3} P^{+}+\mathrm{O}_{2} \rightarrow\left(\mathrm{O}_{2} \ldots \mathrm{H}_{3} P^{+}\right)$

5.Electrochemical reduction of the complex: $\left(\mathrm{O}_{2} \ldots \mathrm{H}_{3} \mathrm{P}^{+}\right)+2 e \rightarrow \mathrm{O}_{2} \mathrm{H}_{3} \mathrm{P}^{-}$

The decomposition of the reduced complex resulting in the reduced form of oxygen and initial porphyrin: $\mathrm{O}_{2} \mathrm{H}_{3} \mathrm{P}^{-} \rightarrow \mathrm{HO}_{2}^{-}+\mathrm{H}_{2} \mathrm{P}$
\end{abstract}

Keywords: Porphyrin, oxygen electroreduction, kinetic current, cyclic voltamperometry, rotating disk electrode, catalysis.

\section{Introduction}

The biological functions of porphyrin molecules are important in the living nature. Therefore, the interest to the chemistry of natural and synthetic porphyrins is continuously increased. However, the many properties of porphyrin were investigated only on the qualitative level due to the low solubility of porphyrins in the most solvents,${ }^{[1]}$ the formation of supramolecular aggregates, ${ }^{[2]}$ the specific of adsorbed behavior at the interface, ${ }^{[3]}$ etc. The porphyrins can include the several reaction centers and different substituents which allow changing its chemical activity and other properties. Despite progress in the synthesis of new porphyrin derivatives, one of the most available synthetic porphyrins is tetraphenylporphine $\left(\mathrm{H}_{2} \mathrm{TPP}\right)$ till now. Extensive investigation of $\mathrm{H}_{2}$ TPP and its derivatives are shown to be prospective in various applications: as the main components of the modern materials for extraction, ${ }^{[4]}$ in the qualitative and quantitative analysis, ${ }^{[5]}$ nonlinear optics, ${ }^{[6]}$ molecular design ${ }^{[7]}$ and medicine. ${ }^{[8,9]}$ It is necessary to note, that for developing of materials for chemical source of electrical energy, ${ }^{[10]}$ sensors $^{[11-13]}$ and solar cells ${ }^{[14]}$ the accurate data on electrochemical and electrocatalytic ${ }^{[15,16]}$ properties of these compounds are required. This work is part of a study aimed for creating porphyrin based materials with practically useful properties and investigates the tetrakis(4'decaoxyphenyl)porphyrin influence on the electrochemical reduction of oxygen on Pt electrode.

\section{Experimental}

Tetrakis(4'-decaoxyphenyl)porphyrin (TDOPP) (Figure 1) was synthesized by condensation of the suitable benzaldehydes 


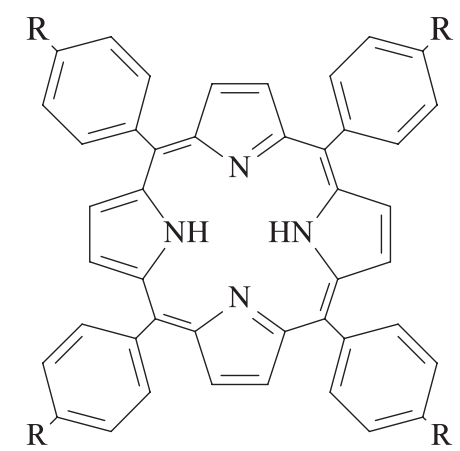

Figure 1. The structure of tetrakis(4'-decaoxyphenyl)porphyrin $\mathrm{R}=-\mathrm{OC}_{10} \mathrm{H}_{21}$.

with pyrrole ${ }^{[17]}$ and purified using column chromatography method with aluminum oxide (Brockmann Activity III). Dimethylformamide (DMF) was used as a solvent. For solvent purification the known method ${ }^{[18]}$ was applied. The residual concentration of water (around $0.06 \%$ ) was determined by Karl Fisher titration method. The solutions were prepared by gravimetric method using electronic analytical balance «Sartorius» ME215S (0.01 mg readability). The TDOPP concentration of $10^{-5} \mathrm{M}$ and base electrolyte - 0.01 $\mathrm{M}$ tetrabutylammonium perchlorate (TBAP) was selected for electrochemical study.

Cyclic voltammograms (CVA) with rotating disk electrode (RDE) were obtained by the automated system constructed on the PI-50-1.1 potentiostat, with an analog-to-digital conversion multichannel programmable broad. The measurements were performed in three-electrode cell with platinum wire as auxiliary electrode (AE) and platinum rod of $2.5 \mathrm{~mm}$ in diameter embedded into fluoroplastic sleeve with an outer diameter of $10 \mathrm{~mm}$ as the working electrode (WE). The WE potential was supported vs. saturated calomel reference electrode (RE) using capillary of Luggin. The capillary was sited facing centre of rotation of WE at distance equal to the outer capillary diameter $(50 \mu \mathrm{m})$. The procedure for the working electrode preparing allows reaching the reproducibility of results: the working area of WE was cleaned fine-grained sandpaper, polished, degreased with alcohol and thoroughly washed with distilled water. After that WE was washed with test solution and placed in the cell. Before measuring the WE was kept in the test solution during 10 minutes for potential stabilization. The accuracy in the determining of potential was $\pm 1 \mathrm{mV}$, the accuracy in the determining of potential current was $2 \%$. Absorption spectra of porphyrin solutions before and after the electrochemical experiments were recorded by "Varian Cary $50 "$ spectrometer.

\section{Results and Discussion}

In the preliminary estimation of CVA technique it was shown that there is an electrochemical window in the range from -1.7 to $+1.7 \mathrm{~V} v s$. SCE in DMF solutions. The limits of the electrochemical window are not changed in the presence of porphyrin and appear due to oxidation and reduction of the solvent and base electrolyte. Within the electrochemical window there are potentials, typical for RedOx processes of porphyrins ${ }^{[19]}$ and for electroreduction of dissolved oxygen. However, direct electrochemical oxidation and reduction of porphyrins were not observed on the CVA curve due to its low concentration. In addition, the position and intensity of the absorption bands character in the spectra of porphyrin solutions (Figure 2) do not change after the electrochemical experiment. It can be explained if under cycling of WE potentials condition the porphyrin electrochemical reactions are reversible or very low in rate. ${ }^{[20]}$ The most probably that small variation of spectra (Figure 2) was caused by the hardware zero drift and slight shift in the concentration of porphyrin due to solvent evaporation.

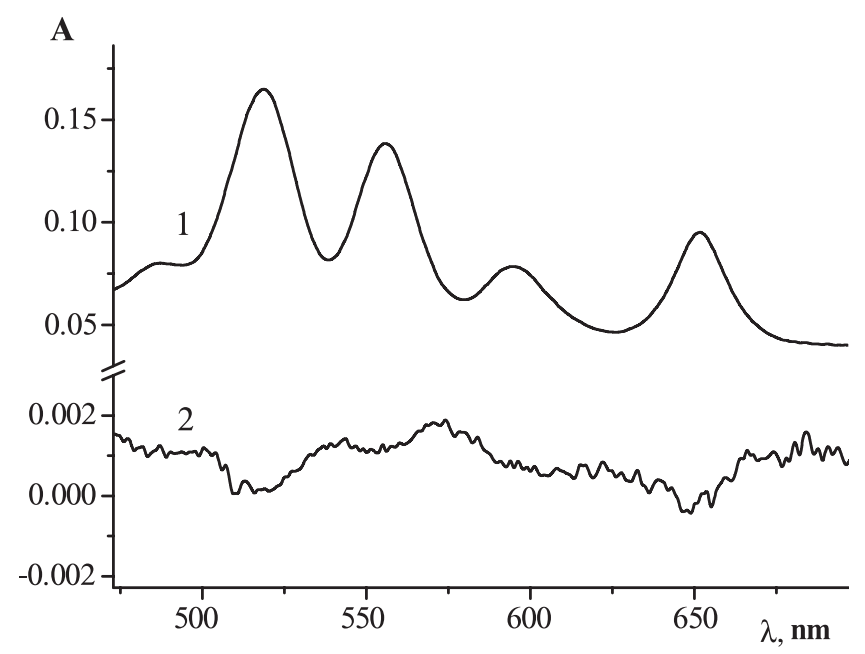

Figure 2. Absorption spectra of tetrakis(4'-decaoxyphenyl)porphyrin in DMF (1); the difference spectrum, which characterizes the changes after the electrochemical experiment (2).

Despite of low porphyrin concentration the effect on the process of electroreduction of oxygen (Figure 3 ) is considerable. The wide (from -0.75 to $-1.5 \mathrm{~V}$ ) and irreversible peak in the CVA curve was attributed with oxygen reduction. The peak value was decreased after bubbling of argon through the solution. The porphyrin adding leads to changes in the shape and intensity of the peak (Figure 3). Such behavior let it to conclude that the peak consist of at least two components (two reduction process) with different influence of the porphyrin on their intensity.

At the same time the rotation rate of electrode affects on the value of current (Figure 4) and it is a common for the oxygen electroreduction processes.

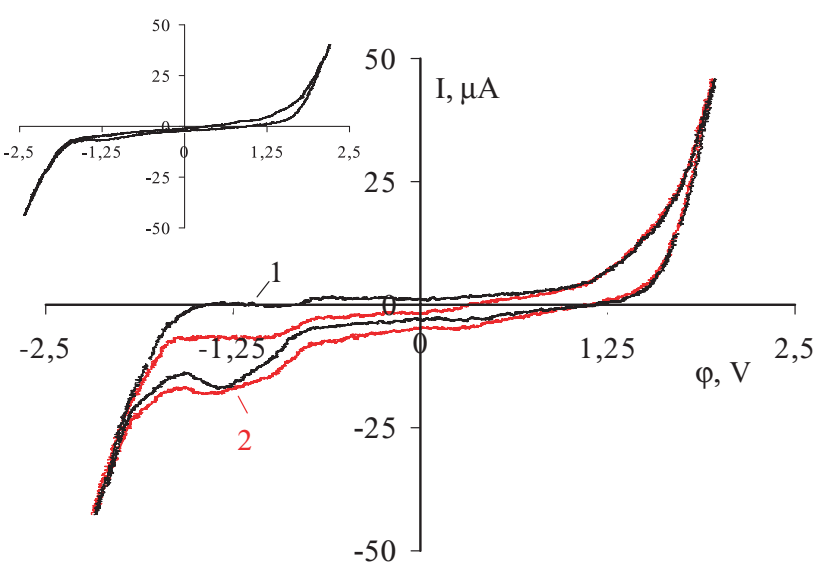

Figure 3. Cyclic voltammograms curves: solutions without (1) and in the presence (2) of TDOPP at natural aeration conditions. Insert shows the CVA curves of deaerated solution without TDOPP. The potential sweep rate was $20 \mathrm{mV} / \mathrm{s}$. 
$\varphi, \mathrm{V}$

$-2$ $-1,5$ $-1$ $-0,5$

0

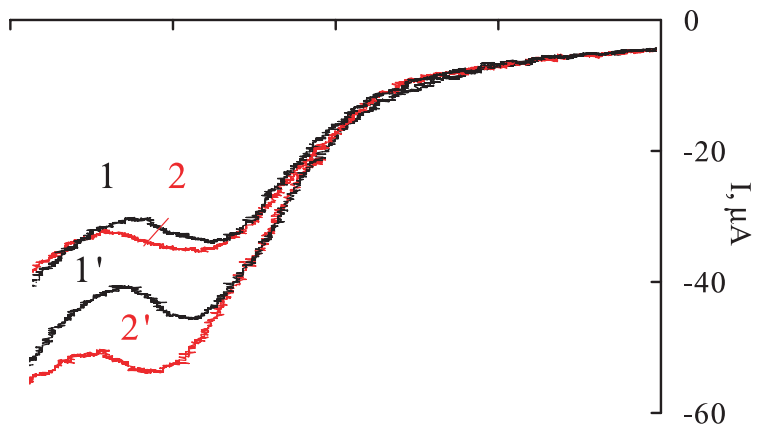

Figure 4. Cathode branch of CVA curves for WE rotational rate $120(1,2)$ and $380\left(1^{\prime}, 2^{\prime}\right) \mathrm{rpm}$. The curves numbering: the solutions without $\left(1,1^{\prime}\right)$ and in the presence $\left(2,2^{\prime}\right)$ of TDOPP. The potential sweep rate was $20 \mathrm{mV} / \mathrm{s}$.

For determining of limiting stage for the oxygen electroreduction the data were represented as cathode current $v s$. the square root of the WE rotation rate dependence (Levich coordinates, Figure 5). It is clear to see that straight lines cannot be extrapolated to the zero point. This fact indicates on process in the mixed mode where diffusion and of electrochemical processes occur with comparable rates. The porphyrin addition leads to increasing in the slope of line, which formally can be regarded as an increase in the effective diffusion coefficient. The break of the straight line indicates that there is an inhibitor in the system, the efficiency of which increases with diffusion limitations decreasing. The
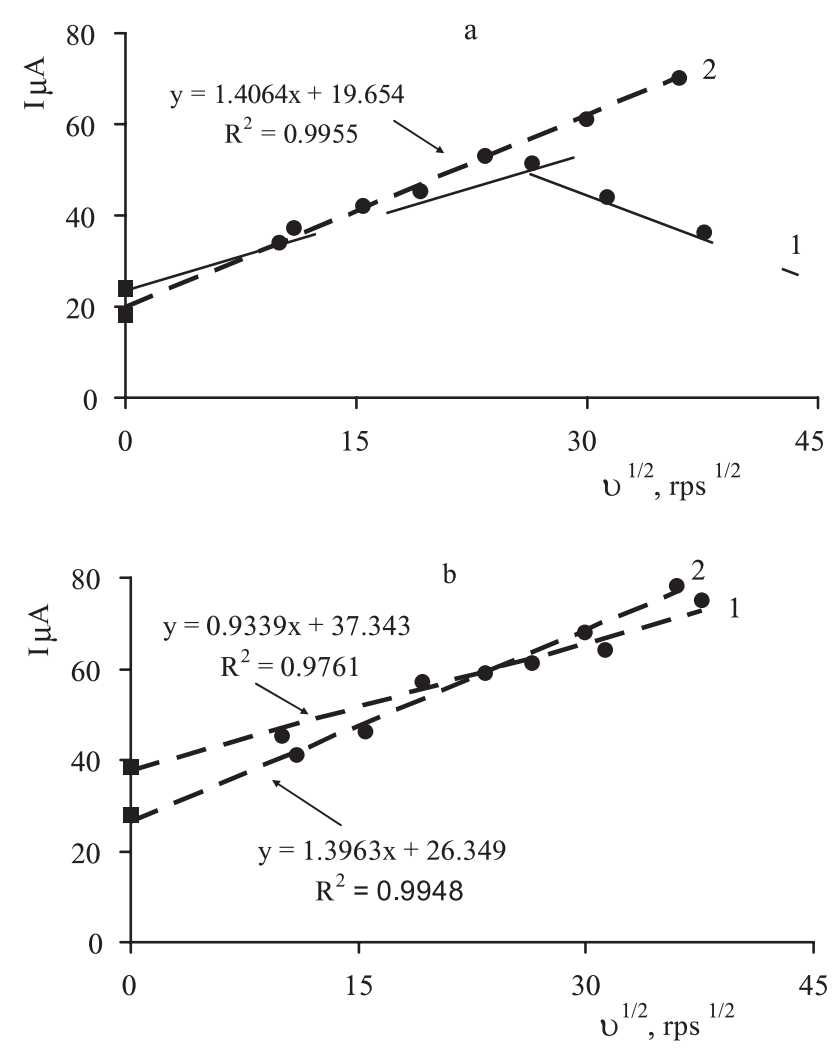

Figure 5. Current plotted in Levich coordinates at potential of oxygen peak maximum (a) and at a potential of $-2 \mathrm{~V}$ (b). 1 - the solutions without and $2-$ in the presence of TDOPP.
$\mathrm{OH}$ radical was specified as inhibitor of electroreduction of oxygen. ${ }^{[21]}$ Its presence on the platinum surface is ensured by the presence of water as impurity of solvent. The absence of a break in the line (2) (Figure 5a) suggests that TDOPP reduces the effect of the inhibitor.

The reduction of oxygen is limited by convective diffusion and kinetic processes (mixed kinetics mode). This condition usually analyzed using the Koutecky-Levich equation: ${ }^{[22]}$

$$
\frac{1}{i}=\frac{1}{i_{\mathrm{k}}}+\frac{1}{i_{\lim }}=\frac{1}{i_{\mathrm{k}}}+\frac{1}{0.62 \mathrm{nFAD}_{\mathrm{o}}^{2 / 3} \omega^{1 / 2} \mathrm{v}^{-1 / 6} \mathrm{C}_{\mathrm{o}}}
$$

where $i_{\mathrm{k}}-$ the kinetic current for oxygen reduction reaction; $i_{\lim }$ - limiting diffusion current; $n-$ the number of electrons involved in the reduction of one oxygen molecule; F Faraday constant; D - diffusion coefficient, $C_{\mathrm{o}}$ - oxygen concentration in the bulk of solution; $v$ - kinematic viscosity; $\omega-\mathrm{WE}$ angular rate.

From the equation it follows that at constant temperature and in the same solution the data plotted as $1 / i$ vs. $1 / \omega^{0.5}$ (Koutecky-Levich coordinates) should be linear. The results (Figure 6) confirm the applicability of this approach for a wide range of WE potentials in the presence and absence of porphyrin. The plot approximation to the infinity WE angular rate allows to estimate the kinetic current. As result it should be conclude that the addition of TDOPP significantly increases the kinetic current of oxygen electroreduction at potentials -1 $\div-1.5 \mathrm{~V}$ (Figure 7), consequently the electrochemical stage of the process is activated.

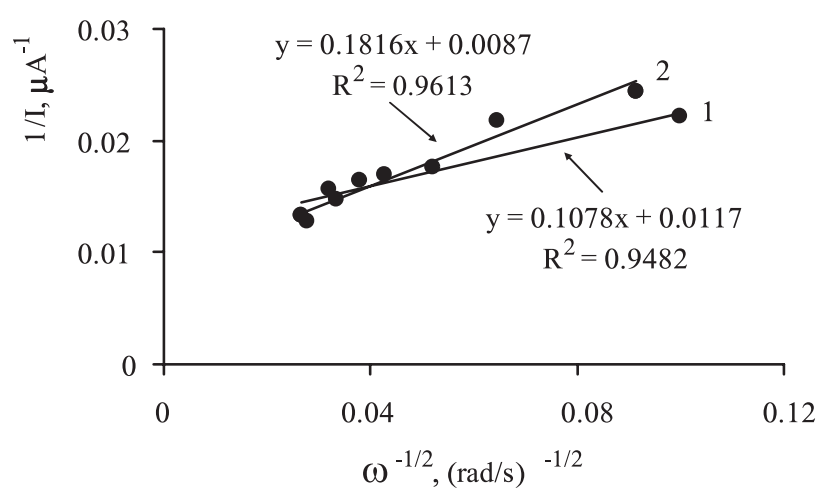

Figure 6. Current plotted in Koutecky-Levich coordinates. 1 - the solutions without and 2 - in the presence of TDOPP.

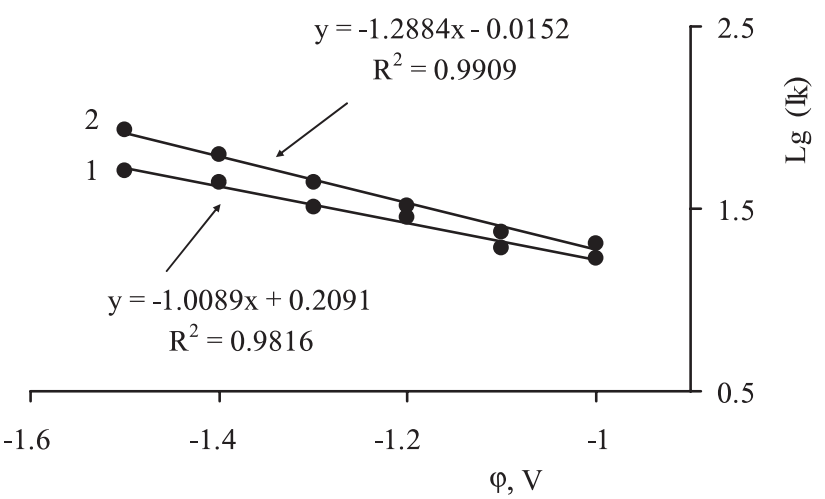

Figure 7. The kinetic current of oxygen electroreduction estimated for potential range $-1 \div-1.5 \mathrm{~V}$. $1-$ the solutions without and $2-$ in the presence of TDOPP. 
The processes of oxygen electroreduction are very important both for technologies and for understanding of the biochemistry of living systems. These processes attract the most careful attention. In particular it is known that in DMF with the impurities of water electroreduction of oxygen occurs on the one-electron mechanism with the formation of superoxide ion: ${ }^{[23]}$

$$
\mathrm{O}_{2}+\mathrm{e} \rightarrow \mathrm{O}_{2}^{-\cdot}
$$

Since the superoxide ion is a strong nucleophile in the presence of water it disproportionates:

$$
\mathrm{O}_{2}^{-} \cdot+\mathrm{H}_{2} \mathrm{O} \leftrightarrow \mathrm{HO}_{2}^{-}+\mathrm{OH}^{-}+\mathrm{O}_{2}
$$

For DMF solutions the reaction (2) is of second order with rate constant about $10^{-3} \mathrm{M}^{-1} \mathrm{~s}^{-1}$.

There is the possibility of self-reducing process of the superoxide ions: ${ }^{[24]}$

$$
2 \mathrm{O}_{2}^{-\bullet} \rightarrow \mathrm{O}_{2}^{2-}+\mathrm{O}_{2}
$$

In the presence of dissolved carbon dioxide the reaction (4) is efficient: ${ }^{[25]}$

$$
2 \mathrm{CO}_{2}+2 \mathrm{O}_{2}^{-} \cdot \mathrm{C}_{2} \mathrm{O}_{6}^{2-}+\mathrm{O}_{2}
$$

The reaction (4) leads to the irreversibility of the oxygen electroreduction, since the binding of the reduced form of oxygen.

The processes (2) - (4) lead to the oxygen concentration increase in the near electrode area due to the decay of superoxide ion. As a result the current limited by oxygen transport will increase ("increase in the effective diffusion coefficient" at formalistic interpretation of data). It can be expected that addition of TDOPP noticeable effects on the electroreduction kinetics oxygen if at least one of the processes $(2)-(4)$ is catalyzed. This assumption is reasonable because the metalloporphyrins and superoxide ion form adducts, the decay of which leads to the disproportionation of superoxide both in water ${ }^{[26]}$ and in aprotic medium. ${ }^{[27]}$ Interaction of superoxide ion with porphyrins ligands was corroborated by spectroscopic data also. ${ }^{[28]}$

On the other hand, metal-free catalysis of electroreduction of oxygen was observed for the protonated forms of porphyrin. ${ }^{[29]}$ Therefore, to explain the increasing of kinetic current at the porphyrin presence condition the following mechanism of oxygen electroreduction can be suggested:

I. The admixture of water is a source of protons in aprotic medium

$$
\mathrm{H}_{2} \mathrm{O} \rightarrow \mathrm{H}^{+}+\mathrm{OH}^{-}
$$

II. The negative WE potential leads to migration of protons due to the electric field and acidification of the near electrode area of the solution

III. The acidic media invokes the formation of the protonated form of porphyrin in the near electrode area of the solution:

$$
\mathrm{H}^{+}+\mathrm{H}_{2} \mathrm{P} \leftrightarrow \mathrm{H}_{3} \mathrm{P}^{+}
$$

IV. Protonated form of porphyrin generates adduct with the dissolved oxygen:

$$
\mathrm{H}_{3} \mathrm{P}^{+}+\mathrm{O}_{2} \rightarrow\left(\mathrm{O}_{2} \ldots \mathrm{H}_{3} \mathrm{P}^{+}\right)
$$

V. Electrochemical reduction of the complex:

$$
\left(\mathrm{O}_{2} \ldots \mathrm{H}_{3} \mathrm{P}^{+}\right)+2 \mathrm{e} \rightarrow \mathrm{O}_{2} \mathrm{H}_{3} \mathrm{P}^{-}
$$

VI. The decomposition of the reduced complex results in the reduced form of oxygen and initial porphyrin:

$$
\mathrm{O}_{2} \mathrm{H}_{3} \mathrm{P}^{-} \rightarrow \mathrm{HO}_{2}^{-}+\mathrm{H}_{2} \mathrm{P}
$$

\section{References}

1. Berezin B.D. Makrotsiclicheskiy effekt i strukturnaya khimiya porfirinov [Macrocyclic Effect and Structural Chemistry of Porphyrins]. Moskva: Krasand, 2010, 424 p. (in Russ.).

2. Wada S., Fujiwara K., Monjushiro H., Watarai H. J. Phys.: Condens. Matter 2007, 19, 1-12.

3. Su B., Li F., Partovi-Nia R., Gros C., Barbe J.-M., Same Z., Girault H.H. Chem. Commun. 2008, 5037-5038.

4. Watarai H., Tsukahara S., Nagatani H., Ohashi A. Bull. Chem. Soc. Jpn 2003, 76, 1471-1492.

5. Zhang Y., Wang H., Yang R.H. Sensors 2007, 7, 410-419.

6. Sendhil K., Vijayan C., Kothiyal M.P. Optical Materials 2005, 27, 1606-1609.

7. Ibrahima H., Kasselouri A., Youb C., Maillardd P., Rosiliob V., Pansuf R., Prognona P. J. Photochem. Photobiol., A 2011, 217, $10-21$.

8. Ol'shevskaya V.A., Zaitseva A.V., Luzgina V.N., Kondratieva T.T., Ivanov O.G., Kononova E.G., Petrovskii P.V., Mironov A.F., Kalinin V.N., Hofmann J., Shtil A.A. Bioorg. Med. Chem. 2006, 14, 109-120.

9. United States Patent 007816518.

10. United States Patent 007927762.

11. Chaniotakis N., Park S., Meyerhoff. M. Anal. Chem. 1989, 61, 566-570

12. Malinowska E., Meyerhoff M. E. Anal. Chim. Acta 1995, 33-43.

13. Rishi K.J., Hamilton A.D. Org. Lett. 2000, 2, 1721-1723.

14. United States Patent 007655961.

15. Noskov A.V., Tesakova M.V., Popov I.A. Izv. Vyssh. Uchebn. Zaved., Khim. Khim Tekhnol. 2011, 54(12), 53-58 (in Russ.).

16. Tesakova M.V., Noskov A.V., Bazanov M.I., Berezina N.M. Zh. Fiz. Khim. 2012, 86, 13-17 (in Russ.).

17. Bikova V.V, Usoltseva N,V., Semeikin A.S., Anan'eva G.A., Karmanova T.V. Zhidkie Kristally 2007, 4(22), 67-74 (in Russ.).

18. Gordon A., Ford G. Sputnik Khimika [Chemists Companion], Moskva: Mir, 1976 (in Russ.).

19. The Porphyrin Handbook (Kadish K.M., Smith K.M., Guilard R., Eds.) Vol. 9, Database of Redox Potentials and Binding Constants. Academic Press, 2000.

20. Tarasevich M.P., Radiushkina K.A., Bogdanovskaya V.A Electrokhimiya porfirinov [Electrochemistry of Porphyrins]. Moskva: Nauka, 1991, 312 p. (in Russ.).

21. Burke L.D., Casey J.K, Morrissey J.A., O'sullivan J.F. J. Appl. Electrochem. 1994, 24, 30-37.

22. Koytetskiy Y.A., Levich V.G. Dokladi AN SSSR 1957, 117 441-444 (in Russ.).

23. Chin D.-H., Chiericato G., Nanni E.J., Sawyer D.T. J. Am Chem. Soc., 1982, 104, 1296-1299.

24. Song Ch., Zhang J. Electrocatalytic Oxygen-Reduction Reaction PEM Fuel Cell Electrocatalysis and Catalyst Layers. 
Fundamentals and Applications (Zhang J., Ed.). Sringer. 2008, $1137 \mathrm{p}$.

25. AlNashef I.M., Leonard M.L., Matthews M.A., Weidner J.W. Ind. Eng. Chem. Res. 2002, 41, 4475-4478.

26. Weinraub D, Levy P, Faraggi M. Int. J. Radiat. Biol. 1986, 50, 649-658.

27. Sawyer D.T., Tsang P.K.S. Free Radical Res. 1991, 12-13, 7586
28. Voicescu M., Ion R., Meghea A. J. Serb. Chem. Soc. 2010, 75, 333-341.

29. Raheleh Partovi NIA. Electrocatalysis at Liquid/Liquid Interfaces. Ch. 7. Assisted Proton Transfer by Free-Base Porphyrin and Catalyzed Oxygen Reduction at Polarized Interface. THÈSE NO 4620, 2010. Laboratoire d'Electrochimie Physique et Analytique, Ecole Polytechnique Fédérale de Lausanne, Switzerland

Received 09.02.2012

Accepted 21.05.2012 